\title{
Beneficios y riesgos para la salud del uso compartido de bicicleta
}

\author{
Health benefits and risks of the sharing use of bicing
}

\section{Objetivo}

Estimar los riesgos y beneficios para la salud de viajar en bicicleta, en un entorno urbano, utilizando un sistema de provisión de bicicletas público ("Bicing"), en comparación con viajar en automotores.

\section{Diseño}

Estudio de evaluación del impacto en salud realizado en Barcelona (España) en el que fueron evaluados 181.982 mayores de 16 años inscriptos en el sistema "Bicing" (11\% de la población).

\section{Evaluación de factores pronósticos y medición de resulta- dos principales \\ El resultado primario medido fue la mortalidad en tres domi- nios: 1) actividad física, 2) contaminación del aire (exposición a partículas menores de $2,5 \mu \mathrm{m}$ ) y 3 ) lesiones no intencionales de tránsito. \\ El resultado secundario fue el cambio en la emisión de dióxido de carbono (CO2). \\ Se calculó el cambio en la mortalidad (aumento o descenso) asociado a la iniciativa "Bicing", calculando los riesgos relativos correspondientes en los tres dominios. Se realizó un análisis de sensibilidad para evaluar el efecto de 12 variables (p. ej. duración del viaje en auto y bicicleta, distancia recorrida, veloci- dad, eventos traumáticos fatales por km recorrido, proporción de la población que utiliza Bicing por día, etc.).}

\section{Resultados principales}

Se calcularon los riesgos relativos $(R R)$ de mortalidad por todas
Rojas-Rueda D y col. BMJ. 2011; 343:d4521

las causas asociadas al ciclismo en comparación a la asociada con los viajes en automóvil, y se expresaron las fracciones atribuibles de mortalidad en la población que utiliza el sistema Bicing. Por último, se calcularon el número anual de muertes. La reducción anual de emisión de CO2 fue de 9.062 toneladas métricas. Ver tabla 1.

Tabla 1: estimación de los principales resultados asociados a la implementación del sistema "bicing" en la ciudad de Barcelona, España.

\begin{tabular}{l|c|c|c}
\multirow{2}{*}{ Variables } & \multirow{2}{*}{$\begin{array}{c}\text { Riesgo } \\
\text { relativo }\end{array}$} & $\begin{array}{c}\text { Impacto poblacional atribuible } \\
\text { al uso de "bicing" }\end{array}$ \\
\cline { 3 - 4 } & & $\begin{array}{c}\text { Fracción de } \\
\text { mortalidad }\end{array}$ & $\begin{array}{c}\text { Número de } \\
\text { muertes al año }\end{array}$ \\
\hline $\begin{array}{l}\text { Número de muertes por colisiones } \\
\text { de tránsito }\end{array}$ & 1,0007 & 0,0007 & 0,03 \\
\hline $\begin{array}{l}\text { Contaminación ambiental (en } \\
\text { partículas menores a 2,5pm) }\end{array}$ & 1,002 & 0,002 & 0,13 \\
\hline Actividad física & 0,80 & $-0,23$ & $-12,46$ \\
\hline
\end{tabular}

\section{Conclusiones}

El uso compartido de la bicicleta en Barcelona demostró disminuir la mortalidad como consecuencia del aumento de la actividad física, no así por los incidentes de tránsito ni por la contaminación del aire. La disminución en la emisión de CO2 representó un $0,9 \%$ en 2009 .

Fuente de financiamiento: Proyecto europeo transporte, actividad física y contaminación ambiental (TAPAS).

\section{Comentario}

El sistema "Bicing" fue implementado en Barcelona durante 2007 con el objetivo de promover el ciclismo urbano para viajes cortos y la multimodalidad en medios de transporte, y aumentar la actividad física, mejorar la calidad del aire y reducir la contaminación. Actualmente cuenta con $146 \mathrm{~km}$ de ciclovías, 425 estaciones y 6000 bicicletas, debiendo ser los usuarios mayores de 16 años y abonar una cuota anual. Vale destacar que otros países de Asia, Europa y América (México DF) ya lo han implementado'.

En la ciudad de Buenos Aires se implementó el programa "Mejor en Bici" desde noviembre de 2010, y actualmente consta con $70 \mathrm{~km}$ de ciclovías, 21 estaciones de recambio y 900 bicicletas. La red recorre la ciudad de Buenos Aires de norte a sur y de este a oeste, conectando puntos neurálgicos de la ciudad. Es gra-tuito, siendo una hora el tiempo máximo permitido en el uso de la bicicleta ${ }^{2}$.

Lamentablemente, el estudio que hemos resumido no ha repor- tado datos del estado basal de las personas "analizadas" (sedentarios vs. deportistas) y/o en la emisión de $\mathrm{CO}_{2}$, de acuerdo al medio de transporte que utilizaran antes de la bicicleta; ni tampoco valoró las emisiones de gases diferentes del $\mathrm{CO}_{2}$. Los resultados reportados sugieren la necesidad de extremar los recaudos de seguridad para los ciclistas.

\section{Conclusiones del comentador}

Este trabajo permite estimar los beneficios del sistema de bicicleta compartida implementado en Barcelona, siendo difícil asemejarlo al sistema de bicicletas compartidas de la Ciudad de Buenos Aires -por el número de estaciones y por la disposición de las ciclovías-, siendo este último de todas maneras un inicio en la política de promover el transporte sustentable.

Camila Roselli [ Servicio de Medicina Familiar y Comunitaria del Hospital Italiano de Buenos Aires. camiros@ hospitalitaliano.org.ar ]

Roselli C. Beneficios y riesgos para la salud del uso compartido de bicicleta. Evid Act Pract Ambul. Ene-Mar 2012; 15(1) 8. Comentado de: RojasRueda D y col. The health risks and benefits of cycling in urban environments compared with car use. BMJ. 2011;343:d4521. PMID: 21816732

\section{Referencias}

1. Rojas-Rueda D y col. The health risks and benefits of cycling in urban environments compared with car use. BMJ. 2011;343:d4521.

2.Gobierno de la Ciudad de Buenos Aires. Programa de Bicicletas en Buenos Aires. "Mejor en Bici". Plan de Movilidad Sustentable. Disponible en URL: http://mejorenbici.buenosaires.gob.ar (último acceso 12/12/2012). 